\title{
45,X/46,XX mosaicism below $30 \%$ of aneuploidy: clinical implications in adult women from a reproductive medicine unit
}

\author{
L Homer $^{1,2,3,4}$, M-T Le Martelot ${ }^{1}$, F Morel ${ }^{2,3,4,5}$, V Amice ${ }^{5}$, V Kerlan ${ }^{2,4,6}$, M Collet ${ }^{1,2,4}$ and M De Braekeleer ${ }^{2,3,4,5}$ \\ ${ }^{1}$ CHU Brest, Service de Gynécologie Obstétrique et Médecine de la Reproduction, CHU MORVAN, 5 Avenue Foch, Brest F-29200, France, \\ ${ }^{2}$ Faculté de Médecine et des Sciences de la Santé, Université de Brest, IFR148 ScInBioS, Brest F-29200, France, ${ }^{3}$ Inserm, UMR_S 613, Brest F-29200, \\ France, ${ }^{4}$ Université Européenne de Bretagne, Brest F-29200, France, ${ }^{5} \mathrm{CHU}$ Brest, Service de Cytogénétique, Cytologie et Biologie de la Reproduction, \\ Brest F-29200, France and ${ }^{6} \mathrm{CHU}$ Brest, Service d'Endocrinologie et Maladies Métaboliques, Brest F-29200, France
}

(Correspondence should be addressed to L Homer at CHU Brest, Service de Gynécologie Obstétrique et Médecine de la Reproduction,

CHU MORVAN; Email: lionelhomer@yahoo.fr)

\begin{abstract}
Objective: Turner's syndrome (TS) is well known, but prognosis for 45,X/46,XX mosaicism below 30\% of aneuploidy has not been established. We evaluated differences in clinical features and biological parameters between patients with numerical sex chromosome mosaicism diagnosed incidentally and control women.

Design: Retrospective observational study of clinical features and biological parameters.

Methods: Standard endocrinological and gynecological examination was done and early-follicularphase blood values were collected from the medical records of women aged 21-43, who were referred to our ward from 1996 to 2006 because of infertility and were karyotyped. Seventy-one women with sex chromosome mosaicism $(45, \mathrm{X} / 46, \mathrm{XX})$ ranging from 4 to $28 \%$ were assigned a chromosomally normal woman $(46, \mathrm{XX})$ matched according to age $(n=71)$.

Results: In group $45, \mathrm{X} / 46, \mathrm{XX}, 8 \%$ or more of aneuploidy accounted for a smaller height compared to controls $(P=0.01)$. Body mass index was increased from $6 \%$ of aneuploidy $(P=0.02)$ and was positively correlated to the percentage of 45 , X cells $(P=0.0001)$; menarche occurred earlier from $10 \%$ of aneuploidy $(P=0.01)$ and was inversely correlated to the percentage of $45, \mathrm{X}$ cells $(P=0.045)$. No difference was found between the groups for FSH, LH, estradiol, inhibin B, and TSH values. Spontaneous abortions were more frequent in case of mosaicism $(P=0.01)$, and recurrence was positively correlated to the percentage of aneuploidy $(P=0.008)$.

Conclusion: Sex chromosome mosaicism is responsible for clinical changes from $6 \%$ of aneuploidy, corresponding to the main phenotypical features of TS.
\end{abstract}

European Journal of Endocrinology 162 617-623

\section{Introduction}

Turner's syndrome (TS) is a dysmorphic syndrome which affects 1 in 2500 to 1 in 3000 liveborn girls. Monosomy X $(45, \mathrm{X})$ represents half of the karyotype spectrum of this syndrome, and the rest includes structural X chromosome abnormalities or mosaicism (1). The main features in adolescence are short stature and primary or secondary amenorrhea because of gonadal dysgenesis. Other impairments consist of heart defect, kidney malformations, overweight, hypothyroidism, ophthalmological and otological defects, gastrointestinal disorders, dermatological pathologies, and neoplasia.

Anyone in whom TS has been established after birth is usually identified by phenotypical features suggestive of this syndrome. Nevertheless, 45,X/46,XX mosaicism could be diagnosed incidentally among common people without noticeable features, or prenatally as a result of amniocentesis in advanced maternal age. Indeed, the percentage of $45, \mathrm{X} / 46, \mathrm{XX}$ mosaicism in the general female population was estimated as $3.1 \%$ by Guttenbach et al. and as $3.5 \%$ by Peschka et al. $(2,3)$. If prognosis of 45 , X monosomy is well known, there is a lack of knowledge concerning mosaic forms, particularly for mosaicism below $30 \%$ of aneuploidy. However, correlation between mosaic and phenotypical or biological parameters has been investigated: follicular counts were increased in individuals with the lowest degree of mosaicism among TS patients (4); Fechner et al. have illustrated a link between FSH value and 45,X/46,XX mosaicism at an early age (5), and a highest frequency of spontaneous menarche was found among women with mosaicism versus nonmosaic TS patients (6).

In addition, the meaning of 'low level' mosaicism for a numerical gonosome anomaly is still being debated. One difficulty comes from the fact that there is no consensus on the definition of low level mosaicism, 
which has been considered by some authors as the presence of $<10 \%$ of abnormal cells $(7-10)$ and by others as the presence of $<6 \%$ of abnormal cells (3).

Having noticed a significant frequency of $45, \mathrm{X} / 46, \mathrm{XX}$ mosaicism in patients referred to our unit of reproductive medicine, we wondered whether this could account for the phenotypical or biological changes related to TS. Insomuch as phenotypical manifestations of TS could be due to either haploinsufficiency of genes in the pseudoautosomal regions of the $\mathrm{X}$ chromosome or aneuploidy itself, we also assumed that clinical features were proportional to the percentage of 45 ,X cells.

Thus, the aim of our study was to assess differences in clinical features and biological parameters between women with numerical sex chromosome mosaicism $(45, \mathrm{X} / 46, \mathrm{XX})$ diagnosed incidentally and control women $(46, \mathrm{XX})$, and also to see if phenotypical signs of TS were correlated to the percentage of aneuploidy among 45,X/46,XX women. At last, comparisons were carried out with successive thresholds of mosaicism to assess if thresholds chosen by cytogeneticists have a clinical significance.

\section{Materials and methods}

\section{Study population}

Women were retrospectively recruited at the Reproductive Medicine Unit of Brest University Hospital from among a population who had been karyotyped from 1996 to 2006 prior to assisted reproductive technologies (ARTs). Investigation of the female partner of infertile patients was done because it was recommended before ARTs $(7,11)$. Indications for karyotypes were unknown at the time of recruitment. Women with sex chromosome aneuploidy were collected in group 1 $(n=71)$; aneuploidy concerned only numerical sex chromosome mosaicism $(45, \mathrm{X} / 46, \mathrm{XX})$ and ranged from 4 to $28 \%$ of 45 ,X cells (Fig. 1 ).

For randomization purposes, a chronological patient list was used. Each woman from group 45,X/46,XX was assigned a control and was matched according to age by picking the next chromosomally normal woman $(46, \mathrm{XX})$ on this list. These control women constituted group 2 or $46, \mathrm{XX}(n=71)$.

All clinical or biological information that was needed was retrospectively collected from medical reports. All 142 women had undergone a routine diagnostic evaluation including a standard endocrinological and gynecological examination; clinical history was taken for menarche, menses, height, body mass index (BMI), and also for spontaneous fertility prior to recruitment.

\section{Laboratory analysis}

Chromosome analysis was carried out on phytohemagglutinin-stimulated peripheral lymphocytes cultured

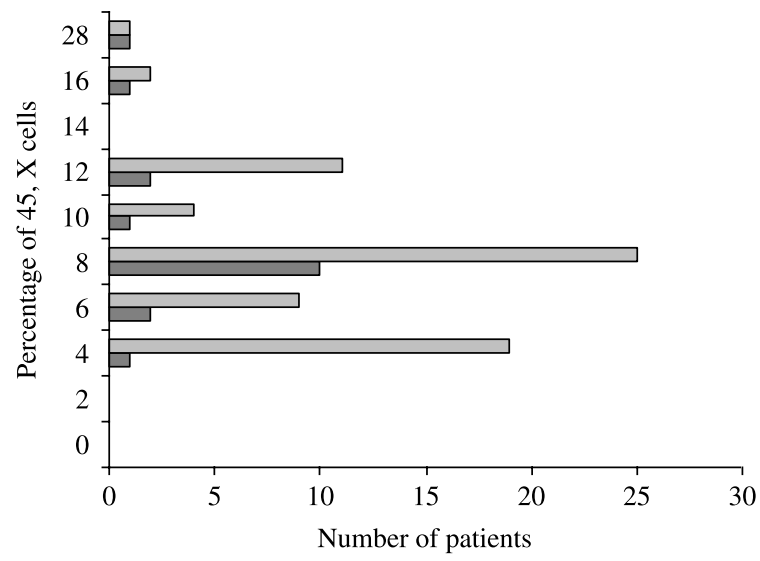

Figure 1 Distribution of $45, \mathrm{X} / 46, \mathrm{XX}$ women according to the percentage of aneuploidy $(n=71)$. Light-gray histograms represent the distribution of $45, \mathrm{X} / 46, \mathrm{XX}$ women according to the percentage of aneuploidy. Most of them had sex chromosome mosaicism equal to or below $12 \%$ of aneuploidy; two women had $16 \%$ of aneuploidy and one woman had $28 \%$ of aneuploidy. Dark-gray histograms represent $45, \mathrm{X} / 46, \mathrm{XX}$ women recruited for partner infertility only $(n=18)$ distributed according to their percentage of aneuploidy. Most of them had $8 \%$ of aneuploidy.

for $72 \mathrm{~h}$. Chromosomes were harvested according to standard procedures, and the R-banded karyotypes were described according to the recommendations of the international system for human cytogenetic nomenclature (12). Sixteen cells were karyotyped. However, if at least one of these 16 cells showed a loss or a gain of a gonosome, the number of analyzed metaphases was increased to 25 . If a second abnormal cell was observed, the analysis was considered to be completed; if not, the number of metaphases was increased to 50 (13).

Early-follicular-phase blood values of FSH, LH, inhibin $\mathrm{B}$, estradiol $\left(\mathrm{E}_{2}\right)$, and TSH were measured in our laboratory at day 2 or 3 of menses. In this part of the study, women with premature ovarian failure (POF) were excluded in each group for FSH, LH, inhibin B, and

Table 1 Indications for karyotypes at the time of recruitment.

\begin{tabular}{|c|c|c|c|}
\hline & $\begin{array}{l}\text { 45,X/46,XX } \\
(n=71)\end{array}$ & $\begin{array}{l}\mathbf{4 6 , X X} \\
(n=71)\end{array}$ & $\boldsymbol{P}$ \\
\hline Prior to IVF & $16.1 \%(11)$ & $19.7 \%(14)$ & 0.66 \\
\hline Prior to ICSI & $60.5 \%(43)$ & $71.8 \%(51)$ & 0.15 \\
\hline Unexplained infertility & $10.3 \%(7)$ & $7.1 \%(5)$ & 0.56 \\
\hline Recurrent pregnancy loss & $10.3 \%(7)$ & 0 & 0.006 \\
\hline $\begin{array}{l}\text { Phenotypical suspicion of } \\
\text { chromosomal abnormality }\end{array}$ & 0 & 0 & \\
\hline Amenorrhea & $4.4 \%(3)$ & $1.4 \%(1)$ & 1.0 \\
\hline
\end{tabular}

Data are expressed in percentage $(n)$. Karyotypes were indicated to investigate women infertility on the one hand, and because it was recommended before ARTs in the female partner of infertile patients on the other hand. Indications for karyotypes were unknown at the time of recruitment. Karyotypes were more often carried out in case of recurrent pregnancy loss in group $45, \mathrm{X} / 46, \mathrm{XX}$ than in group $46, \mathrm{XX}(P=0.006)$. 
Table 2 Demographic data and main features of groups $45, \mathrm{X} / 46, \mathrm{XX}(n=71)$ and $46, \mathrm{XX}(n=71)$.

\begin{tabular}{llll}
\hline & $\begin{array}{l}\mathbf{4 5 , X / 4 6 , X X} \\
(n=71)\end{array}$ & $\begin{array}{l}\mathbf{4 6 , X X} \\
(n=71)\end{array}$ & $\boldsymbol{P}$ \\
\hline Age (years) & $33.9 \pm 4.3$ & $33.4 \pm 3.9$ & 0.31 \\
Dysmenorrhea & $25.8 \%(15 / 58)$ & $33.3 \%(22 / 66)$ & 0.36 \\
Secondary infertility & $52.1 \%(37 / 71)$ & $40.8 \%(29 / 71)$ & 0.13 \\
Smoking & $33.8 \%(24 / 71)$ & $38.0 \%(27 / 71)$ & 0.36 \\
Menarche (years) & $13.2 \pm 1.3$ & $13.0 \pm 1.3$ & 0.53 \\
Menses (days) & $29.6 \pm 5.1$ & $30.0 \pm 6.7$ & 0.72 \\
BMl (kg/m ( $\left.^{2}\right)$ & $23.5 \pm 4.3$ & $23.6 \pm 4.5$ & 0.92 \\
Height $(\mathrm{cm})$ & $163 \pm 6$ & $164 \pm 6$ & 0.19 \\
\hline
\end{tabular}

Data are expressed as mean \pm 1 S.D., or percentage $(n)$. The two groups did not differ in age at recruitment, either in main phenotypical features of Turner's syndrome (menarche, menses, body mass index, or height) or for parameters that influence spontaneous fertility (menses, BMI, dysmenorrhea, or smoking). Data were missing for dysmenorrhea in each group. BMI, body mass index.

$\mathrm{E}_{2}$ assessments ( $n=3$ in group $45, \mathrm{X} / 46, \mathrm{XX} ; n=2$ in group $46, \mathrm{XX})$. POF was defined by a 6 -month period of amenorrhea and a FSH level higher than $40 \mathrm{UI} / \mathrm{l}$.

\section{Statistical analysis}

Three kinds of comparisons were carried out:

- First, comparisons were made between groups 1 $(45, \mathrm{X} / 46, \mathrm{XX})$ and $2(46, \mathrm{XX})$.

- Secondly, group 1 women were compiled in successive sub-samples according to the percentage of aneuploidy: $4-6 \%(n=28)$ versus $8-28 \%(n=43)$, then $4-8 \%(n=53)$ versus $10-28 \%(n=18)$, and lastly, $4-10 \% \quad(n=57)$ versus $12-28 \% \quad(n=14)$. Sub-samples were compared with one another, and with controls.

- Thirdly, we restricted our study to women recruited for male infertility only to avoid possible bias in female subjects' sampling. In this part of the study, compilations among 45,X/46,XX women were not allowed because samples were smaller $(n=18$ in group 45,X/46,XX; $n=33$ in group $46, \mathrm{XX})$.

Data are expressed as the mean \pm 1 S.D. unless otherwise stated. Statistical analyses were performed by unpaired Student's $t$-test and $\chi^{2}$ test. ANOVA was used to test for differences among more than two independent groups. GraphPad Prism software (version 4.0; GraphPad Software, San Diego, CA, USA) was used to perform Spearman's rank correlation. Spearman's rank correlation was used to test the direction and strength of the relationship between the percentage of aneuploidy and menarche, height, BMI, and miscarriage recurrence.

$P<0.05$ was considered significant.

\section{Results}

\section{Demographic data}

No TS was diagnosed in patients of any group.

Figure 1 represents 45,X/46,XX women distributed according to their percentage of aneuploidy. Most of them had sex chromosome mosaicism equal to or lower than $12 \%$ of aneuploidy; two women had $16 \%$ of aneuploidy and one woman had $28 \%$ of aneuploidy.

No difference was found between the groups as to why couples referred to our unit of reproductive medicine. These indications were those habitually observed for ARTs: tubal factor, endometriosis, dysovulation, diminished ovarian reserve, recurrent spontaneous abortion (RSA), and male factor, mixed or idiopathic.

Indications for karyotypes did not differ between groups, except for recurrent pregnancy loss, which was seen more often in group 45,X/46,XX (Table 1).

\section{Clinical status}

Menarche, menses, height, and BMI did not differ between the two groups (Table 2); nevertheless, differences were found after sampling 45,X/46,XX women according to their percentage of aneuploidy. First, we observed that aneuploidy above or equal to $8 \%$ accounted for a smaller height compared to both controls and women with aneuploidy below or equal to $6 \%(160 \pm 6$ vs $164 \pm 6 \mathrm{~cm} ; P=0.02$; Table 3$)$; $45, \mathrm{X} / 46, \mathrm{XX}$ women were also shorter than controls when groups were restricted to women recruited for male infertility only $(160 \pm 6$ vs $165 \pm 6 \mathrm{~cm} ; P=0.02)$. Secondly, BMI was significantly higher from $6 \%$ of aneuploidy among 45,X/46,XX women (24.4 \pm 4.4 vs $\left.21.6 \pm 4.1 \mathrm{~kg} / \mathrm{m}^{2} ; \quad P=0.01\right)$, and overweight

Table 3 Clinical features according to karyotype. 45,X/46,XX women are sub-sampled according to the percentage of aneuploidy: 4- 6 vs $8-28 \%$. Data are expressed in mean $\pm 1 \mathrm{~s}$.

\begin{tabular}{llccccc}
\hline & & Age (years) & Menarche (years) & Menses (days) & Height $(\mathrm{cm})$ & BMI $\left(\mathrm{kg} / \mathrm{m}^{2}\right)$ \\
\hline $45, \mathrm{X} / 46, \mathrm{XX}$ & $4-6 \%(n=28)$ & $34.9 \pm 4.0$ & $13.5 \pm 1.2$ & $28.6 \pm 3.9$ & $164 \pm 6^{\dagger}$ & $21.9 \pm 4.1^{\dagger}$ \\
$46, \mathrm{XX}$ & $8-28 \%(n=43)$ & $33.2 \pm 4.8$ & $12.8 \pm 1.3$ & $29.7 \pm 5.3$ & $160 \pm 6^{\dagger, *}$ & $24.7 \pm 4.2^{\dagger}$ \\
$P$ & $(n=71)$ & $33.4 \pm 3.9$ & $13.0 \pm 1.3$ & $30.0 \pm 6.7$ & $164 \pm 6^{*}$ & $23.6 \pm 4.5$ \\
\hline
\end{tabular}

Comparisons were made between group $46, X X$ and sub-samples of group $45, X / 46, X X$ according to the percentage of aneuploidy (4-6 vs $8-28 \%$ ). Women with aneuploidy above or equal to $8 \%$ were shorter than both controls $\left({ }^{\star} P=0.02\right)$ and women with aneuploidy below or equal to $6 \%$ ( $\left.{ }^{\dagger} P=0.02\right)$, and also had higher BMI than women with aneuploidy below or equal to $6 \%\left({ }^{\dagger} P=0.01\right)$. 
Table 4 Clinical features according to karyotype. 45,X/46,XX women were sub-sampled according to the percentage of aneuploidy: $4-8$ vs $10-28 \%$.

\begin{tabular}{llccccc}
\hline & & Age (years) & Menarche (years) & Menses (days) & Height $(\mathrm{cm})$ & BMI $\left(\mathrm{kg} / \mathrm{m}^{2}\right)$ \\
\hline $45, \mathrm{X} / 46, \mathrm{XX}$ & $4-8 \%(n=53)$ & $33.4 \pm 4.6$ & $13.5 \pm 1.3^{*}$ & $29.3 \pm 4.6$ & $163 \pm 6$ & $22.7 \pm 4.2^{*}$ \\
& $10-28 \%(n=18)$ & $35.1 \pm 4.0$ & $12.3 \pm 1.0^{*}$ & $30.5 \pm 6.5$ & $161 \pm 6$ & $25.7 \pm 4.1^{*}$ \\
$46, \mathrm{XX}$ & $(n=71)$ & $33.4 \pm 3.9$ & $13.0 \pm 1.3$ & $30.0 \pm 6.7$ & $164 \pm 6$ & $23.6 \pm 4.5$ \\
$P$ & & 0.28 & 0.01 & 0.45 & 0.26 & 0.01
\end{tabular}

Data are expressed as mean \pm 1 s.D. Comparisons were made between group $46, X X$ and sub-sample of group $45, X / 46, X X$ according to the percentage of aneuploidy (4-8 vs 10-28\%). Women with aneuploidy above or equal to $10 \%$ had earlier menarche and higher BMI than women with aneuploidy below or equal to $8 \%\left({ }^{\star} P=0.01\right)$.

occurred from $10 \%$ of aneuploidy $\left(25.7 \pm 4.1 \mathrm{~kg} / \mathrm{m}^{2}\right.$; Tables 3 and 4). Furthermore, BMI was positively correlated to the percentage of $45, \mathrm{X}$ cells $(P=0.0001)$. Lastly, no woman had primary amenorrhea, and all women had spontaneous menarche in both groups. However, menarche occurred earlier in group $45, \mathrm{X} / 46, \mathrm{XX}$ when the percentage of aneuploidy reached $10 \%$ or more than in women with aneuploidy below or equal to $8 \%(12.3 \pm 1.0$ vs $13.5 \pm 1.3$ years; $P=0.01$; Table 4). Moreover, age of menarche was inversely correlated to the percentage of $45, \mathrm{X}$ cells in the group 45,X/46,XX $(P=0.045)$.

\section{Biological changes}

No difference was found between the two groups for early-follicular-phase blood values of FSH $(8.41$ \pm 2.6 vs $8.28 \pm 4.0 \mathrm{UI} / \mathrm{l} ; \quad P=0.85)$, LH $(4.99 \pm 3.4$ vs $5.04 \pm 2.3 ; P=0.89), \mathrm{E}_{2}(50.6 \pm 23.7$ vs 51.7 $\pm 32.1 \mathrm{pg} / \mathrm{ml} ; \quad P=0.81)$, inhibin $B(55.5 \pm 36.5$ vs $57.4 \pm 33.7 \mathrm{pg} / \mathrm{ml} ; P=0.80)$, or TSH $(1.74 \pm 0.8$ vs $1.83 \pm 1.1 \mu \mathrm{UI} / \mathrm{ml} ; P=0.64)$. However, differences appeared after pooling 45,X/46,XX women depending on their percentage of aneuploidy: $E_{2}$ level was significantly increased in women with $6 \%$ or less of aneuploidy than in women with $8 \%$ or more of aneuploidy $\quad(58.1 \pm 14.6$ vs $46.1 \pm 19.6 \mathrm{pg} / \mathrm{ml}$; $P=0.03) . E_{2}$ level was also significantly increased in women with $10 \%$ or less of aneuploidy than in women with $12 \%$ or more of aneuploidy $(52.7 \pm 19.2$ vs 37.7 $\pm 17.9 \mathrm{pg} / \mathrm{ml}$; $P=0.02$ ). Furthermore, $E_{2}$ level was inversely correlated to the percentage of aneuploidy in group 45,X/46, XX $(P=0.02)$. No more difference was found for the other parameters after sub-sampling $45, \mathrm{X} / 46, \mathrm{XX}$ women.

\section{Spontaneous fertility}

Three and two women had POF diagnosed at the time of recruitment in groups $45, \mathrm{X} / 46$, XX and $46, \mathrm{XX}$ respectively. The frequencies of POF were 4.2 and $2.8 \%$ in these groups respectively $(P=\mathrm{NS})$.

The mean number of first trimester pregnancy losses per patient was $2.0 \pm 0.9$ in group $45, \mathrm{X} / 46, \mathrm{XX}$ and was $1.2 \pm 0.4$ in group $46, \mathrm{XX}(P=0.01)$. Frequency of spontaneous pregnancy loss was significantly increased in group 45,X/46,XX than in group 46,XX (48.9 vs $24.1 \% ; P=0.0026$ ). There was also a positive correlation between the recurrence of spontaneous miscarriage and the percentage of $45, \mathrm{X}$ cells in group 45,X/46, XX $(P=0.026)$. Complementary investigations were carried out in group 45,X/46, XX, and they revealed two women with Hashimoto's disease, one woman with heterozygous prothrombin mutation, and two women with a FSH level higher than $15 \mathrm{UI} / \mathrm{l}$ as a possible other etiology for RSA. Having excluded these women, positive correlation was still significant $(P=0.008)$.

\section{Discussion}

Clinically, we confirmed that the main phenotypical features of TS are visible even in the case of mosaicism below $30 \%$ of 45 ,X cells. Moreover, it seems to appear as from $6 \%$ of aneuploidy, which has not been demonstrated yet. However, phenotypical expression level depends on the feature studied.

First, short stature is one of the cardinal symptoms of TS, and the mean final height of patients without recombinant human GH is habitually $20 \mathrm{~cm}$ shorter than the mean height of normal female population from the same country. Thereby, mean height of TS patients in France is $142 \mathrm{~cm}$ (14), whereas mean normal height is $163 \mathrm{~cm}$ (15). It is known that TS patients with mosaicism are often taller than $45, \mathrm{X}$ monosomic patients (16), but are also shorter than normal women. Although it appears in our study that the heights of the two groups are not so different from the heights of the French normal population, mosaicism involves shorter height from $8 \%$ of aneuploidy. Genetically, short stature homebox gene located in the pseudoautosomal regions of X (Xp11-22) and Y (Yp11) is implicated in skeletal growth troubles by haploinsufficiency in TS patients (17). Women with this deletion have less important growth failure ( -2 s.D.) than women with monosomy or important $\mathrm{X}$ short arm deletions ( -3 s.D.) (18). Another gene located between regions Xp11.2 and Xp22.1 was implicated in height regulation (19); it seems that patients with this deletion had normal stature, but were nonetheless smaller than expected considering their parents' 
heights. In our study, X chromosome haploinsufficiency is involved in height regulation by a global gene haploinsufficiency, but mosaicism below 28\% does not induce significant growth failure.

Secondly, TS is associated with overweight after the age of 5 (20). In our study, BMI was also influenced by mosaicism with a positive correlation between BMI and the percentage of 45 ,X cells. However, the hypothesis of gene haploinsufficiency for overweight was not upheld by Ohman et al. because of a candidate locus for obesity located on X short arm Xp24 (21). Nevertheless, Bakalov et al. demonstrated an insulin secretion defect in TS patients compared with both 46 , XX patients with diminished ovarian reserve and controls matched according to age (22); they illustrated that haploinsufficiency of genes located on $\mathrm{X}$ chromosome accounted for pancreatic $\beta$-cell impairment. This finding could partly explain the positive correlation demonstrated in our study, with proportional pancreatic cell impairment depending on the percentage of aneuploidy. However, this hypothesis was not tested in our study because of the use of a retrospective method.

The fact that BMI and height achieve statistical significance at a different cut point is probably a random variation in our study. Indeed, height is always negatively correlated to BMI, so as the group becomes more severely affected, height will decline and BMI will go up. However, it is possible that the lack of significance for the height of the patients from $6 \%$ of aneuploidy is linked to the inadequate size of the sample: small height variations will significantly affect BMI, as it is squared on the denominator, but the sample is probably too small (18 subjects with $4 \%$ of aneuploidy) to achieve significance between groups 4 and $6-28 \%$ women of $45, X$ cells $(164 \pm 6$ vs $162 \pm 6 \mathrm{~cm} ; P=N S)$. More investigations are necessary to conclude on this point.

Thirdly, we demonstrated that all patients with sex chromosome mosaicism had spontaneous menarche. This notion was illustrated by Pasquino et al. for whom most TS patients with spontaneous menarche were those with mosaicism; indeed, in 69 patients over 12 and for whom TS was diagnosed, 63\% had spontaneous pubertal development and 50\% had spontaneous menarche at the mean \pm s.E.M. age of $13.2 \pm 1.5$ (6). Nevertheless, the authors did not specify the percentage of aneuploidy in this group. The age of menarche in France is 12.6 (23), which is not different from that of our control group $(13.0 \pm 1.3)$. In our study, earlier menarche was found for women with mosaicism above or equal to $10 \%$, as well as an inverse correlation between menarche and the percentage of $45, \mathrm{X}$ cells. Thus, the mean age of menarche is earlier in sub-sample $45, \mathrm{X} 10-28 \%(12.3 \pm 1.0)$ than in both general population and sub-sample 45,X 4-8\%. Nevertheless, age of menarche in sub-samples is in the normal range in France. Spontaneous menarche occurs only if follicles are present in the ovary. Hreinsson et al. have found follicles in eight ovarian cortical biopsies of TS women, and demonstrated that follicular density was inversely correlated to FSH level, but also that follicular counts were increased in individuals with the lowest degree of mosaicism (4), meaning that early follicle depletion due to $\mathrm{X}$ haploinsufficiency causes earlier menarche. This contradicts the data of Lachlan et al. who have demonstrated that menarche occurs later $(14.2 \pm 1.5$ years) in case of deletions proximal to Xp22.1, and leads to more frequent POF (24). In our study, 45,X/46,XX patients with confirmed POF $(n=3)$ also had belated menarche $(14.0 \pm 0$ years), but no other women with menarche after 14 had POF. On this ground, it has been demonstrated that age at menarche is not affected by menopausal age, even in case of POF (25). It would mean that the more the aneuploidy increases, the more the oocyte depletion increases, which leads to primary amenorrhea. Therefore, sex chromosome mosaicism below $30 \%$ of aneuploidy leads to earlier menarche, but does not involve more POF in our study.

As phenotypical consequences of mosaicism had been found, the same repercussions on spontaneous fertility were expected. Indeed, TS is one of the genetic etiologies of infertility and is associated with ovarian failure or recurrent pregnancy loss in cases of preserved fertility (1). We investigated two features indicating the ovarian reserve: early-follicular-phase blood values and spontaneous fertility. Surprisingly, the results proved conflicting: in our study, no obvious difference arose from usual tests of ovarian reserve between 45,X/46,XX women and controls, whereas mosaicism was associated with increased first trimester pregnancy terminations. Concerning biological values, differences were significant only among sub-samples in group $45, \mathrm{X} / 46, \mathrm{XX}$ but never between $45, \mathrm{X} / 46$, XX subsamples and control women. However, the highest mean $\mathrm{E}_{2}$ levels did not reach that considered as poor prognostic value $(>80 \mathrm{pg} / \mathrm{ml})$ by Smotrich et al. at day 2 or 3 of menses (26), which means the tests used in our study were not discriminating enough, or mosaicism had no real impact on ovarian reserve. Parameters with more sensitivity to answer this question may be lacking in our study because of our retrospective study range starting from 1996 to 2006, we had neither antral follicular count nor anti-Mullerian hormone assessments, which now seem to provide more discriminating acuteness in adulthood (27-29). However, these parameters would not have shown any difference between groups 45,X/46,XX and 46,XX since Sonntag et al. had found no difference in assisted reproductive technology results between the two corresponding groups, which is considered the best ovarian reserve test (10). Therefore, in our study, sex chromosome mosaicism below $30 \%$ has no impact on the ovarian reserve of females.

Although expected results were not found for the assessment of ovarian reserve in group 45, X/46, XX, important consequences for spontaneous fertility were shown, among which was the unfavorable prognosis 
in the first trimester of pregnancy. Nevertheless, the impact of sex chromosome mosaicism on RSA is disputed. The significant difference found for the mean number of first trimester abortions between groups 45,X/46,XX and 46,XX might be due to a recruitment bias: seven karyotypes were requested for RSA in group 1 , but none in the control group $(P=0.006)$. Yet, the significant correlation found between the recurrence of abortion and the percentage of 45 , $X$ cells was independent of any recruitment bias, all the more so because correlation was still significant after excluding women with other etiologies for RSA. These results are in contrast to those reported by Horsman et al., who illustrated in 1987 that mosaicism frequency was not higher in a population with RSA $(1.5 \%)$ than in a control group without RSA (30); however, the percentage of mosaicism in their study group did not exceed $10 \%$ of aneuploidy, whereas the most numerous pregnancy losses concerned women with $12 \%$ aneuploidy in our study. On the other hand, RSA in 45,X mosaic patients could rather be the result of an increased rate of diminished ovarian reserve according to Kuo \& Guo (31); this was not confirmed in our study either. On the contrary, these results suggest a conduction of the aneuploidy to the oocyte nucleus without repercussion on follicular atresia, thus confirming the known impact of parental chromosome aberrations on abortions (32). Therefore, could the observed changes possibly be the result of mosaicism limited to tissues? Two authors have demonstrated that aneuploidy can be found in different parts of the ovary: in cortical biopsies by de Grouchy et al. (33), and in granulosa cells among 16 patients of the study (F Gallon, F Morel, V Amice \& M De Braekeleer, unpublished observations) by us. It means that mosaicism below 30\% of aneuploidy has physical repercussions but does not induce endocrine ovarian defect although it is transmitted to the ovary. It is known that only one $\mathrm{X}$ is required for ovarian differentiation (34), but two are required for ovarian maintenance (35). Several studies have shown that proximal $\mathrm{Xq}$ and proximal Xp contain regions of importance to ovarian maintenance, among them are Xq13 and Xp11. Deletions in these areas are responsible for POF. Nevertheless, some authors consider that impaired ovarian development is due to the length of the lacking region rather than to specific genes during meiosis (18). According to our study, it seems that $30 \%$ of aneuploidy does not negatively affect ovarian maintenance, but it could be transmitted to the oocyte.

\section{Conclusion}

We can conclude that sex chromosome mosaicism that is diagnosed incidentally has a clinical impact from $6 \%$ of aneuploidy in adulthood. This result corroborates data found in childhood, even if age-dependent loss of $\mathrm{X}$ chromosome is confirmed $(18,36)$. While no consensus has been established on cytogenetic grounds for the definition of low level sex chromosome mosaicism, we have demonstrated that the clinical threshold seems to be $6 \%$. This result has an important significance particularly for the prenatal screening of such aneuploidy. Parents can be reassured about their descendants as far as phenotypical feature prognosis is concerned, as well as for spontaneous pubertal development. Nevertheless, patients should be informed about the likelihood of higher rates of first trimester miscarriage.

\section{Declaration of interest}

The authors declare that there is no conflict of interest that could be perceived as prejudicing the impartiality of the research reported.

\section{Funding}

This research did not receive any specific grant from any funding agency in the public, commercial, or not-for-profit sector.

\section{References}

1 Sybert VP \& McCauley E. Turner's syndrome. New England Journal of Medicine 2004351 1227-1238.

2 Guttenbach M, Koschorz B, Bernthaler U, Grimm T \& Schmid M. Sex chromosome loss and aging: in situ hybridization studies on human interphase nuclei. American Journal of Human Genetics $1995571143-1150$

3 Peschka B, Leygraaf J, Van der Ven K, Montag M, Schartmann B, Schubert R, van der Ven H \& Schwanitz G. Type and frequency of chromosome aberrations in 781 couples undergoing intracytoplasmic sperm injection. Human Reproduction $1999 \mathbf{1 4}$ $2257-2263$

4 Hreinsson JG, Otala M, Fridstrom M, Borgstrom B, Rasmussen C, Lundqvist M, Tuuri T, Simberg N, Mikkola M, Dunkel L \& Hovatta $\mathrm{O}$. Follicles are found in the ovaries of adolescent girls with Turner's syndrome. Journal of Clinical Endocrinology and Metabolism $2002873618-3623$.

5 Fechner PY, Davenport ML, Qualy RL, Ross JL, Gunther DF, Eugster EA, Huseman C, Zagar AJ \& Quigley CA. Differences in follicle-stimulating hormone secretion between 45 , X monosomy Turner syndrome and 45,X/46,XX mosaicism are evident at an early age. Journal of Clinical Endocrinology and Metabolism 200691 4896-4902.

6 Pasquino AM, Passeri F, Pucarelli I, Segni M \& Municchi G. Spontaneous pubertal development in Turner's syndrome. Italian Study Group for Turner's Syndrome. Journal of Clinical Endocrinology and Metabolism 199782 1810-1813.

7 Meschede D, Lemcke B, Exeler JR, De Geyter C, Behre HM, Nieschlag E \& Horst J. Chromosome abnormalities in 447 couples undergoing intracytoplasmic sperm injection - prevalence, types, sex distribution and reproductive relevance. Human Reproduction $199813576-582$.

8 Scholtes MC, Behrend C, Dietzel-Dahmen J, van Hoogstraten DG, Marx K, Wohlers S, Verhoeven H \& Zeilmaker GH. Chromosomal aberrations in couples undergoing intracytoplasmic sperm injection: influence on implantation and ongoing pregnancy rates. Fertility and Sterility $1998 \mathbf{7 0} 933-937$.

9 Gekas J, Thepot F, Turleau C, Siffroi JP, Dadoune JP, Briault S, Rio M, Bourouillou G, Carre-Pigeon F, Wasels R \& Benzacken B. Chromosomal factors of infertility in candidate couples for ICSI: an equal risk of constitutional aberrations in women and men. Human Reproduction 200116 82-90. 
10 Sonntag B, Meschede D, Ullmann V, Gassner P, Horst J, Nieschlag E \& Behre HM. Low-level sex chromosome mosaicism in female partners of couples undergoing ICSI therapy does not significantly affect treatment outcome. Human Reproduction $2001 \mathbf{1 6}$ 1648-1652.

11 Mau UA, Backert IT, Kaiser P \& Kiesel L. Chromosomal findings in 150 couples referred for genetic counselling prior to intracytoplasmic sperm injection. Human Reproduction $199712930-937$.

12 ISCN. An International System for Human Cytogenetic Nomenclature. Eds Shaffer LG \& Tommerup N. Basel Switzerland: S. Karger, 2005.

13 Morel F, Gallon F, Amice V, Le Bris MJ, Le Martelot MT, Roche S, Valeri A, Derrien V, Herry A, Amice J \& De Braekeleer M. Sex chromosome mosaicism in couples undergoing intracytoplasmic sperm injection. Human Reproduction $2002172552-2555$.

14 Rochiccioli P, Battin J, Bertrand AM, Bost M, Cabrol S, le Bouc Y, Chaussain JL, Chatelain P, Colle M, Czernichow P, David M, Job JC, Lecornu M, Leheup B, Pierson M, Limal JM, Mariani R, Ponte C, Rappaport R \& Tauber M. Final height in Turner syndrome patients treated with growth hormone. Hormone Research 1995 44 172-176.

15 de Saint Pol T. L’obésité en France: les écarts entre catégories sociales s'accroissent. INSEE Premiére 20071123 1-4.

16 Battin J. Turner syndrome and mosaicism. Bulletin de l'Académie Nationale de Médecine 2003187 359-367 (discussion 368-370).

17 Rao E, Weiss B, Fukami M, Rump A, Niesler B, Mertz A, Muroya K, Binder G, Kirsch S, Winkelmann M, Nordsiek G, Heinrich U, Breuning MH, Ranke MB, Rosenthal A, Ogata T \& Rappold GA. Pseudoautosomal deletions encompassing a novel homeobox gene cause growth failure in idiopathic short stature and Turner syndrome. Nature Genetics 199716 54-63.

18 Ogata $\mathrm{T} \&$ Matsuo N. Turner syndrome and female sex chromosome aberrations: deduction of the principal factors involved in the development of clinical features. Human Genetics $199595607-629$.

19 Zinn AR, Tonk VS, Chen Z, Flejter WL, Gardner HA, Guerra R, Kushner H, Schwartz S, Sybert VP, Van Dyke DL \& Ross JL. Evidence for a Turner syndrome locus or loci at Xp11.2-p22.1. American Journal of Human Genetics 199863 1757-1766.

20 Cabrol S. Turner syndrome. Annales d'Endocrinologie 200768 2-9.

21 Ohman M, Oksanen L, Kaprio J, Koskenvuo M, Mustajoki P, Rissanen A, Salmi J, Kontula K \& Peltonen L. Genome-wide scan of obesity in Finnish sibpairs reveals linkage to chromosome Xq24. Journal of Clinical Endocrinology and Metabolism 200085 3183-3190.

22 Bakalov VK, Cooley MM, Quon MJ, Luo ML, Yanovski JA, Nelson LM, Sullivan G \& Bondy CA. Impaired insulin secretion in the Turner metabolic syndrome. Journal of Clinical Endocrinology and Metabolism 200489 3516-3520.

23 De La Rochebrochard E. The age at puberty for girls and boys in France. Population 199954 933-962.

24 Lachlan KL, Youings S, Costa T, Jacobs PA \& Thomas NS. A clinical and molecular study of 26 females with Xp deletions with special emphasis on inherited deletions. Human Genetics 2006 118 640-651.

25 Progetto Menopausa Italia Study Group. Premature ovarian failure: frequency and risk factors among women attending a network of menopause clinics in Italy. BJOG : an International Journal of Obstetrics and Gynaecology 2003110 59-63.

26 Smotrich DB, Widra EA, Gindoff PR, Levy MJ, Hall JL \& Stillman RJ. Prognostic value of day 3 estradiol on in vitro fertilization outcome. Fertility and Sterility $1995 \mathbf{6 4} 1136-1140$.

27 Fanchin R, Schonauer LM, Righini C, Guibourdenche J, Frydman R \& Taieb J. Serum anti-Mullerian hormone is more strongly related to ovarian follicular status than serum inhibin B, estradiol, FSH and LH on day 3. Human Reproduction $2003 \mathbf{1 8}$ 323-327.

28 Fanchin R, Taieb J, Lozano DH, Ducot B, Frydman R \& Bouyer J. High reproducibility of serum anti-Mullerian hormone measurements suggests a multi-staged follicular secretion and strengthens its role in the assessment of ovarian follicular status. Human Reproduction 200520 923-927.

29 Hazout A, Bouchard P, Seifer DB, Aussage P, Junca AM \& Cohen-Bacrie P. Serum antiMullerian hormone/Mullerianinhibiting substance appears to be a more discriminatory marker of assisted reproductive technology outcome than folliclestimulating hormone, inhibin B, or estradiol. Fertility and Sterility 200482 1323-1329.

30 Horsman DE, Dill FJ, McGillivray BC \& Kalousek DK. X chromosome aneuploidy in lymphocyte cultures from women with recurrent spontaneous abortions. American Journal of Human Genetics $1987 \mathbf{2 8}$ 981-987.

31 Kuo PL \& Guo HR. Mechanism of recurrent spontaneous abortions in women with mosaicism of X-chromosome aneuploidies. Fertility and Sterility 200482 1594-1601.

32 Boue JG, Boue A \& Lazar P. Chromosome aberrations in abortions. Annales de Genetique 196710 179-187.

33 de Grouchy J, Lamy M, Frezal J \& Ribier J. XX/XO mosaics in Turner's syndrome. Two further cases. Lancet $1961 \mathbf{1}$ 1369-1371.

34 Ogata T, Muroya K, Matsuo N, Shinohara O, Yorifuji T, Nishi Y, Hasegawa Y, Horikawa R \& Tachibana K. Turner syndrome and Xp deletions: clinical and molecular studies in 47 patients. Journal of Clinical Endocrinology and Metabolism 2001 86 5498-5508.

35 Simpson JL \& Rajkovic A. Ovarian differentiation and gonadal failure. American Journal of Human Genetics 199989 186-200.

36 Abruzzo MA \& Hassold TJ. Etiology of nondisjunction in humans. Environmental and Molecular Mutagenesis 199525 $38-47$.

Received 3 November 2009

Accepted 5 November 2009 